\title{
Un nuevo \\ pacto social \\ para la función
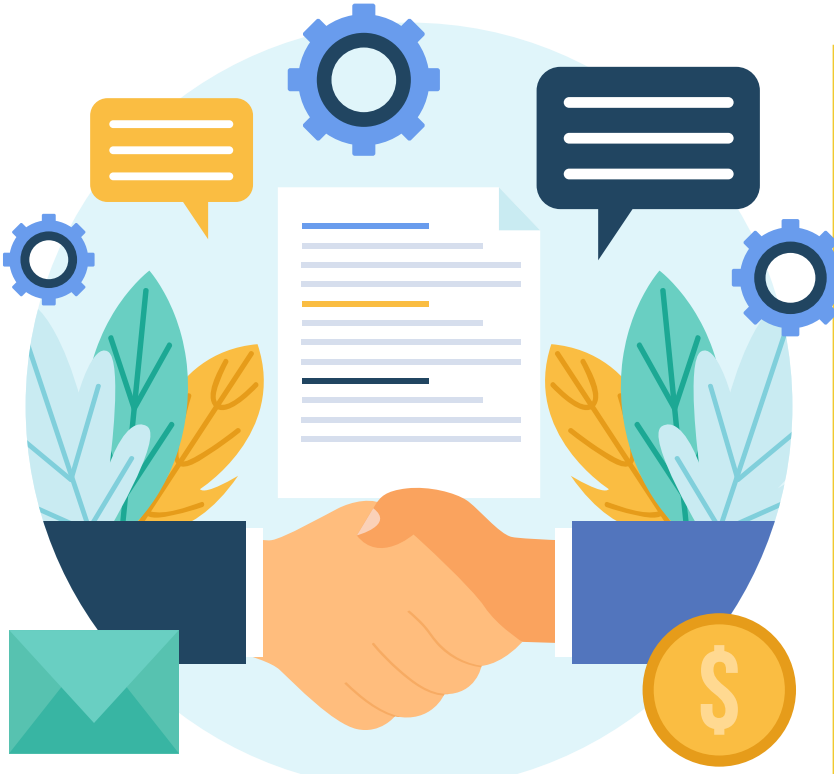 pública
}

Eduardo Abarzúa C. PhD. en Ciencias del Trabajo, Universidad Católica de Lovaina, Bélgica. Decano Facultad de Economía y Negocios, Universidad Alberto Hurtado. Consejero del Consejo de Alta Dirección Pública

A más de un año de la masiva expresión de malestar social que inundó nuestro país, nos encontramos próximos a definir los términos en que se estructurará una nueva Constitución.

En ese contexto, se hace necesario concordar nuevos criterios respecto del tratamiento constitucional de la función pública, cuya calidad resulta crítica tanto para hacer frente a la complejidad que ha alcanzado la gestión del Estado como para salvar la brecha que existe entre las demandas ciudadanas y la capacidad de los agentes públicos para satisfacerlas.

El proceso constituyente provee la oportunidad de establecer una nítida separación entre la política y la función pública, de modo de distinguir entre gobernantes y asesores políticos de exclusiva confianza, por una parte y funcionarios, por la otra. Los primeros, abocados a impulsar el programa que la ciudadanía respaldó con su voto $y$, los segundos, a atender en forma regular y continua las necesidades sociales, implementando, ejecutando y administrando políticas públicas en el ámbito de sus competencias. Esta diferenciación obedece a su distinta naturaleza y persigue evitar interferencias que, de no proscribirse, nos condenan al clientelismo, al cortoplacismo y al populismo, además de desaprovechar sinergias, complementariedades y equilibrios entre ambas esferas.

La separación que se propone consagrar constitucionalmente, tiene consecuencias relevantes que, por obra de la supremacía de la carta fundamental, deberían reflejarse en futuras leyes y en ajustes a la normativa imperante sobre la materia.

En primer lugar, facilitaría la distinción entre políticas de Estado -concebidas para el largo plazo, en respuesta a objetivos nacionales- y de Gobierno. Al efecto, debe tenerse en cuenta que, en nuestro país, la mayoría de los servicios públicos sectoriales -en los más variados ámbitos-, ejecutan políticas públicas permanentes o de largo plazo, que trascienden los cambios de gobierno y que, en lo sucesivo, podrían proyectarse y ejecutarse bajo esa lógica. Lo anterior, sin perjuicio del deber funcionario de responder a las directrices ministeriales y ejecutar, con profesionalismo y neutralidad, las políticas gubernamentales.
En segundo lugar, la separación entre política y función pública facilitaría la efectiva profesionalización de los estamentos directivos de la Administración, responsables de liderar los servicios públicos. Los que no deberían ser incluidos entre el personal de libre remoción gubernamental.

Cabe señalar que, en nuestra historia reciente, la creación de la Alta Dirección Pública significó un importante primer paso en esta dirección, al apostar por optimizar la entrega de bienes y servicios a la ciudadanía y el cumplimiento de políticas y programas definidos por la autoridad, por medio de la selección basada en mérito de los equipos directivos del gobierno central. No obstante, la decisión de entregar a la autoridad gubernamental la facultad de removerlos discrecionalmente -coherente con el exacerbado presidencialismo del modelo imperante-, ha hecho zozobrar el intento de avanzar hacia una gerencia pública profesional. Lo que queda de manifiesto al constatar, tras sucesivos cambios de coalición gober- crear una institucionalidad responsable de contratar, evaluar desempeño, gestionar talento y desvincular funcionarios, que garantice la excelencia profesional, la eficacia indiferente frente a la línea ideológica gubernamental, la adscripción irrestricta a los principios de buen gobierno y la mejora continua en la gestión de los servicios públicos, la que debería radicarse en un órgano del más alto nivel de influencia y autonomía, obligado a rendir cuenta y responder ante la ciudadanía. Este organismo debería establecer estándares de integridad, propiciar avances en equidad remuneracional, diversidad e inclusión, además de relaciones laborales basadas en el respeto a los derechos fundamentales en el trabajo, constituyendo al Estado en un referente en la materia.

En consistencia con lo anterior, no se puede soslayar la necesidad de eliminar de la Constitución las actuales limitaciones al ejercicio de la negociación colectiva y la huelga para los trabajadores del sector público, lo que resulta anacrónico, en pleno siglo XXI, considerando que

\section{"EI proceso constituyente provee la oportunidad de establecer una nítida separación entre la política y la función pública, de modo de distinguir entre gobernantes y asesores políticos de exclusiva confianza, por una parte y funcionarios, por la otra"}

nante, que -con independencia de quien ocupe La Moneda- cerca de dos tercios de estos directivos son desvinculados en los dos primeros años de gobierno, por consideraciones mayoritariamente asociadas al interés de nombrar a un sucesor de confianza política.

En tercer lugar, como contrapartida al punto anterior, el Gobierno debería poder contar con personal de confianza, que le provea de asesoría en la gestión política, reforzando la imparcialidad de la función pública permanente. Sus nombramientos deberían excluirse del principio de acceso en base a concurso público, permaneciendo en sus cargos mientras cuenten con la confianza de la autoridad y sin proyectarse más allá del respectivo período presidencial.

Un cuarto aspecto dice relación con la necesidad de nuestro país ha ratificado convenios internacionales que reconocen tales derechos.

Finalmente -para complementar y potenciar aún más las posibilidades que abriría este nuevo pacto social para la función pública-, la nueva Constitución debería crear un ente público responsable de llevar a cabo la prospección de estrategias de desarrollo y el diseño de políticas de Estado de largo plazo, el que debería ser encabezado por un Consejo autónomo integrado por expertos nominados por actores ampliamente representativos de la comunidad nacional

Los desafíos que tenemos por delante son enormes. Chile y su futuro nos obligan a alcanzar consensos en torno a las mejores fórmulas para construir el país que heredaremos a las nuevas generaciones. $\mathbf{E}$ 